\title{
PAIN IN PARAPLEGIA
}

\begin{abstract}
'As you ought not to attempt to cure eyes without head, or head without body, so you ought not to treat body without mind.'
\end{abstract}

Socrates, c. 400 B.C.

\author{
By Dr. David C. Burke, M.B., B.S.(Melb.), D.P.R.M. \\ Spinal Injury Centre for Victoria, Austin Hospital-Heidelberg, Victoria, Australia
}

PAIN is defined by the Concise Oxford Dictionary as 'suffering, distress of body or mind'. This definition implies the unpleasant nature of pain, both as a physical entity and a psychological entity, but perhaps Sherrington's (I952) definition is the best as he described pain as the 'psychical adjunct of an imperative protective reflex'. This means that pain is part of a withdrawal response to limit the damage caused by a noxious stimulus with a psychological component. That pain has a physical component, mediated by specific nerve endings, nerve fibres and nerve pathways in the spinal cord to a localised area of the brain is now a well established anatomical and physiological fact. But for some time now it has also been clear to physicians that the response to a given painful stimulus is variable from individual to individual, and that there is an important psychological component to the sensation of pain.

Chronic pain has long been recognised as a complication of spinal paralysis, and is generally classified into three common types:

I. Localised or somatic root pain.

2. Visceral pain-cramping, diffuse and vague.

3. Diffuse pain in areas with sensory loss (central or phantom-limb pain, including the 'causalgia' of cauda equina lesions) - burning, tingling, poorly localised.

Bors (I95I, I959) claimed that some type of phantom sensation is present in all cases of spinal cord injury, as after amputation, the sensations usually declining with time. Weinstein (I962) also found phantom sensations in Ioo per cent. of patients with spinal cord lesions but, unlike Bors, did not find fading of the phantom as he did with amputees. Sometimes these phantom sensations are painful; more often they are a discomfort which may be interpreted as pain. Riddoch (I94I) considered that the phantoms of spinal cord lesions, unlike those of amputations, were more often discomforts than pains and were more intense with low lesions than with high lesions. Weinstein (I962) found that 64 per cent. of I 50 patients with spinal cord lesions described a 'burning' sensation in some part of their body below the level of paralysis, and that it was an 'unpleasant' sensation. The lower incidence of pain in cervical injuries, compared to thoracic and complete conus and cauda equina injuries, was also observed by Botterell et al. (1953). Evans (I962) encouraged seven patients with complete paraplegia of more than three months' duration to give a detailed account of the subjective sensations in their legs. 
The predominant sensations, although described in terms of pain, heat or pressure, were not distressing. Rossier (I964) and Botterell et al. (I953) stressed the variation in the intensity of the pain with emotional, exogenous and endogenous factors. Whereas a state of well-being was associated with a decrease in the pain, psychological problems such as anxiety, hostility, sexual problems and frustration may increase it. The intensity of pain, particularly the diffuse, central type, has been observed to vary with the weather, fatigue, infections, spasticity, distension of viscera, smoking, drinking, infected pressure sores, constipation and calculi.

The incidence of pain in paraplegia varies according to different authors. Davis and Martin (I947) found that over 90 per cent. of 47I patients with spinal cord injuries complained of diffuse, burning pains at some time following the injury, twenty-seven per cent. (I26 patients) of the severe cases required the consideration of active steps to be taken for relief. Botterell et al. (I953) found pain in II 8 (94 per cent.) of I25 patients with traumatic lesions and Bors (I959) found some type of pain or discomfort in 90 per cent. of cases after injury. The majority of the patients in these three series had sustained war injuries; a high proportion being open injuries of the spine. At the other extreme, Munro (1948) found that 65 patients out of 99 with spinal cord injuries resulting from the war had no pain on discharge from hospital. Another 27 had minor degrees of pain and only six patients ( 6 per cent.), all cauda equina lesions, had disabling pain on discharge. Botterell et al. (1953) found 30 per cent. with severe pain. Kennedy (1946) considered that one third to one half of patients will have some form of unpleasant sensory disturbance, which is more or less persistent, but less than Io per cent. have pain persistent or severe enough to require surgical intervention. Poer (I946) reported only I 6 per cent. of patients with war injuries had severe pain, 57 per cent. of these having had laminectomies. Munro (I950) analysing 69 patients with pain out of 228 patients admitted to a Veterans Centre found that over 50 per cent. had a pain of the nerve root type. No comparative figures for civilian paraplegic populations were obtained.

The subject of pain in paraplegia has not attracted much attention in the literature. For example, there has not been a single article specifically on the subject of pain in the International Fournal of Paraplegia since its inception in 1963. Much of the published material has been in the neurosurgical journals this being mainly concerned with the evaluation of results from a variety of surgical procedures for the relief of chronic pain. Other writers, such as Bors (I95 I, I959, I963) and Riddoch (I9I7-I8, I94I) have attempted to explain the phenomenon of phantom pain, but there does not appear to be any systematic attempt to evaluate the factors producing or aggravating pain in paraplegia. There would appear to be a place for such a study as the incidence of pain in paraplegics has been reported by different authors to vary between about 90 per cent. and 30 per cent. of a large series of patients; and severe pain has been reported to be from as low as $I^{\circ} 6$ per cent. to as high as 27 per cent. Obviously there must be a variation in the definition of pain by different writers to account for some of these differences, but it seems likely that there is also a real difference in the incidence at different hospitals. It was felt that a study of the possible factors producing this difference might add to the knowledge on the causes of pain in paraplegia. The author was able to make such a study as he had the opportunity of working on the staff of two different Spinal Injury Centres in different countries. 


\section{METHOD}

While working with the staff of the Spinal Cord Injury Service at Rancho Los Amigos Hospital, (U.S.A.) during 1970, the author observed a basically similar philosophy and method of treatment of spinal paralytics to those practised in the Spinal Injuries Unit of the Austin Hospital, Heidelberg, Australia. However, a strong clinical impression was gained to imply that there was a greater incidence of pain among the Rancho patients than those at Austin. As there were obvious differences in the patients admitted to the two Centres and differences in the details of management, both before and during treatment at the Centre, it was felt that it might be fruitful to make a comparative study of this problem of pain. The findings and conclusions made in this study are those of the author and are not necessarily the opinions of the staff of either of the hospitals at which the study was made.

The first task was to establish whether or not there was a difference in the incidence of pain between the two Centres. If this was so, the next step was to make a detailed study of the patients complaining of pain so as to try to isolate any painproducing factors. As pain is so difficult to define, and even more difficult to measure, it was decided to do a series of spot surveys of each Unit to estimate the number of patients with 'significant pain' at those times. A patient was considered to have significant pain if he or she continually complained and/or received analgesic drugs regularly. All sites and causes of pain were included. As pain may be chronic or episodic, and patient populations can vary, a spot survey was carried out on three separate days, each a month apart, at the two Centres on the first of October, November and December 1970, at Rancho, and the first of March, April and May, 1971, at Austin. In an attempt to maintain consistency of the evaluation of the presence or absence of significant pain, the author personally reviewed all the patients in each Centre on the days of the survey. To avoid objective error or prejudice, one of the nurses in charge of each ward was also consulted on each occasion. A high level of agreement between the author and the nurses was invariably obtained.

As it was felt that errors of both omission and addition might be introduced the patients were not interviewed. The difficulties in evaluating pain in these patients include: the interpretation of phantom sensations by the patient as pain; confusion of the symptoms; fear of something not understood, and often not explained, and, occasionally, a deliberate attempt to attract the attention of nursing staff. It is appreciated that one could be criticised for not including the patient in the consultations and evaluations, but it was felt that an experienced doctor and nurse, who knew the patient well, could make a more objective evaluation of the presence of pain. The author does not, and cannot, claim a survey of this type to be very accurate, but feels this type of analysis to be as accurate as possible with such a vague symptom, and in the absence of a reliable scientific instrument such as a 'pain meter'.

The size of the two Units used in this study is roughly comparable with 75 beds at Rancho Los Amigos Hospital and 65 at Austin Hospital. The turnover of patients at Rancho is considerably higher than at Austin. Both hospitals are 'non private' and therefore receive patients of a comparable socio-economic background. 


\section{RESULTS AND DISCUSSION}

Incidence of Pain. The number of patients considered to have significant pain, as defined, in the two Centres at the time of the spot survey, is shown in Table I. It will be seen that there was a higher number and percentage at Rancho Los Amigos Hospital than at Austin Hospital. As the method of judging 'significant' pain was somewhat arbitrary and dependent on a subjective impression, the figures could not be subjected to statistical analysis. But it is considered that the difference in the figures for the two Centres is so great as to represent a significant difference in the incidence of pain between the two hospitals.

Table II depicts the variation in incidence of pain at the different times of the survey and from ward to ward. There was some variation in a particular ward at different times through changes in ward population and other factors, but the

TABLE I

Incidence of Pain

\begin{tabular}{|l|r|r|} 
& Austin & Rancho \\
\hline Number of patients with pain & 22 & 97 \\
Number of inpatients at time of surveys & 156 & 214 \\
Percentage of patients with pain & $14 \%$ & $45 \%$ \\
\hline
\end{tabular}

TABLE II

Variation of Incidence by Time and Ward

\begin{tabular}{|c|c|c|c|c|}
\hline $\begin{array}{l}\text { Austin } \\
\text { Ward A }\end{array}$ & $\begin{array}{c}\text { I March I97I } \\
20 \%\end{array}$ & $\begin{array}{c}\text { I April I97I } \\
2 \mathrm{I} \%\end{array}$ & $\begin{array}{c}\text { I May I97I } \\
\text { I } 8 \%\end{array}$ & $\begin{array}{c}\text { Overall } \\
20 \%\end{array}$ \\
\hline $\begin{array}{l}\text { 'Acute' ward } \\
\text { Ward B } \\
\text { Ward C }\end{array}$ & $\begin{array}{l}18 \% \\
27 \%\end{array}$ & $\overline{10 \%}$ & $\begin{array}{r}16 \% \\
5 \%\end{array}$ & $\begin{array}{l}\text { I0. } 5 \% \\
14 \%\end{array}$ \\
\hline $\begin{array}{l}\quad \text { Rancho } \\
\text { Ward A } \\
\text { 'Acute' ward }\end{array}$ & $\begin{array}{c}\text { I Oct. I970 } \\
65 \%\end{array}$ & $\begin{array}{c}\text { I Nov. I970 } \\
44 \%\end{array}$ & $\begin{array}{c}\text { I Dec. I970 } \\
69 \%\end{array}$ & $\begin{array}{c}\text { Overall } \\
59 \%\end{array}$ \\
\hline $\begin{array}{l}\text { Ward B } \\
\text { Ward C }\end{array}$ & $\begin{array}{l}32 \% \\
50 \%\end{array}$ & $\begin{array}{l}37 \% \\
57 \%\end{array}$ & $\begin{array}{l}35 \% \\
39 \%\end{array}$ & $\begin{array}{l}34 \cdot 5 \% \\
49 \%\end{array}$ \\
\hline
\end{tabular}

incidence followed a similar pattern for each ward. The reasons for such a variation will be discussed later.

It will be noted that the percentage of patients with pain is greatest in the 'acute' ward of both Centres. This was to be expected, as this ward contains the most recently injured patients. However, there is a significant difference between the two Centres as to the type of patients nursed in this ward. At Austin new patients are normally admitted directly to the Centre within 24 hours of onset of injury (Io of the I4 patients in this survey) and remain in the acute ward for eight to 
I2 weeks after injury, whereas at Rancho new patients are admitted between one week and one year after injury; the majority (30 of 46 patients in this survey) between two weeks and three months. Patients remain in the acute ward at Rancho for a variable period depending on spinal stability, level of lesion and other factors. At Rancho it is mainly tetraplegics who are nursed in the acute ward; at Austin there is no such selection; they are admitted to the acute ward as they are admitted to the Centre, whether paraplegic or tetraplegic.

Patients will usually have some pain in the spine at the site of injury, but this rarely lasts for more than a week. This may be considered to account for the higher incidence of pain in the acute wards, but there is still room for explanation as to why there was 59 per cent. with pain at Rancho compared to Austin's 20 per cent. when the former's new patients are admitted so much later. Psychological reactions to severe disability are a real cause of excessive response to painful stimuli and a higher incidence in the newly injured would be expected. Differing philosophies of the psychological management of the disabled patient may account for a major disparity in the incidence of pain in new patients; certainly the ability of individual members of staff in this respect can be important as suggested by the variations of pain in different wards.

Analysis of Patients with Pain. There were I7 patients at Austin who had pain at least once in the survey and 57 at Rancho. The majority of patients were aged between 16 and 30 years; those at Rancho being on average six years younger (Table III), so the age distribution of patients with pain was that of the

TABLE III

Age of Patients

\begin{tabular}{|c|c|c|}
\hline Age & Austin & Rancho \\
\hline $0-20$ & I & 9 \\
$2 \mathrm{I}-30$ & 4 & 25 \\
$3 \mathrm{I}-40$ & 2 & 7 \\
$4 \mathrm{I}-50$ & 6 & 8 \\
$5 \mathrm{I}-60$ & 3 & 5 \\
60 & $\mathrm{I}$ & 3 \\
\hline Average & 38 & $32 \cdot 6$ \\
\hline & years & years \\
\hline
\end{tabular}

patient population at Rancho but in an older age bracket at Austin. No other explanation is offered for this difference except to say that it is the author's experience to usually find greater difficulties of adaptation to disability in the older agegroups.

Thirteen of the I7 patients at Austin were male, a slightly higher proportion of females than in the general patient population of the Centre, while at Rancho there were 35 males and $\mathbf{2 2}$ females, which is a significantly higher proportion of females than that of the general patient population, Wilcox et al. (I970).

The racial origin of the patients is shown in Table IV. All I7 Austin patients 
were Caucasian, but six of these were recent immigrants to Australia, two from Yugoslavia and one each from Malta, Holland, Hungary and Ireland. There was only one recent immigrant, from Portugal, of the 38 Caucasian patients at Rancho. The proportion of Negro and Mexican patients with pain is well in excess of their proportion of the population of Southern California, but closely approximates to the proportions of the races of patients admitted to Rancho Los Amigos Hospital in I968 (Ikuta, I970). Thus, the only racial tendency towards a higher incidence of pain in this survey is a disproportionate number of recent immigrants in the Austin series, but the numbers are too small to draw any definite conclusions. New arrivals to any country are always unsettled and could be expected to show an excessive reaction to stress, such as illness. A lower pain threshold among the Southern European migrants has been commonly observed at the Austin.

TABLE IV

Race of Patients

\begin{tabular}{|l|c|c|}
\hline & Austin & Rancho \\
\hline Caucasian & I7 & 38 \\
Negro & 0 & 8 \\
Mexican & 0 & I I \\
\hline
\end{tabular}

TABLE V

Number of Appearances in Survey*

\begin{tabular}{|l|r|r|r|r|c|c|}
\hline & \multicolumn{3}{|c|}{ Austin } & \multicolumn{3}{|c|}{ Rancho } \\
\cline { 2 - 7 } & New & Readmit & Total & New & Readmit & Total \\
\hline Once only & IO & 2 & I2 & 2I & 8 & 29 \\
Twice & 4 & I & 5 & I5 & 3 & I8 \\
Three times & 0 & 0 & 0 & I0 & I & I I \\
\hline
\end{tabular}

* One Rancho patient appeared twice, as a first admission and subsequently as a re-admission. One Austin patient who appeared twice had two quite different causes for his pain.

Number of Admissions. The proportion of patients with pain who were re-admissions to the Centre rather than first admissions was about the same for both Centres (about 20 per cent.). These proportions were probably not significantly different from those of the re-admissions among the patient population of both Centres.

In an attempt to ascertain any difference in the severity and chronicity of the complaints of pain between new and re-admitted patients, the number of appearances in the survey of the two groups were compared. Table $\mathrm{V}$ does not indicate any difference between the two groups at either Centre, but does indicate a greater 
chronicity of pain at Rancho that at Austin. Eleven patients had 'significant pain' at each of the three spot surveys separated by a period of two months at Rancho, whereas no Austin patients appeared three times.

Analysis of Re-admissions. It was considered that a close scrutiny of re-admitted patients might give some useful information on the factors leading to excessive pain, as all were well past the time when they could be expected to have pain from an acute injury to the spine, and most should have had time to adapt to their disability.

The three Austin patients, aged between 45 and 55 years, had been disabled for between three and I4 years and had incomplete neurological lesions with sensory sparing. All three had a genuine, organic basis for their pain, namely osteoarthritis of the lumbar spine, an infected amputation stump and abdominal surgery one week before the survey. It is considered that their disability had no relation to the pain they complained of, except that its degree was perhaps overstated. Two of them were habitually heavy consumers of analgesics (oral) for the relief of pain.

The Rancho re-admissions were generally younger, their ages ranging between $2 \mathrm{I}$ and 57 years. Their period of disability varied between six months and 28 years (average nine years). The great majority had complete neurological lesions, and four were tetraplegics. Five of the I 2 Rancho patients had an adequate, non-spinal basis for their pain, such as recent surgery. Three of the remainder had a diffuse phantom pain below the lesion, two had chronic upper extremity pain, another a chronic groin pain (probably a TI2 root pain) and one had a longstanding pain down the whole of one side of the body. Six of these seven patients had been re-admitted because of pressure sores. Rossier (1964) has drawn attention to the frequent association of chronic pain and pressure sores. Four of the Rancho readmissions were known chronic drug abusers and another five were 'probables'75 per cent. of this group of patients. The nature of the drugs taken was not known with certainty in each case, but three were thought to take heroin regularly (by injection), the remainder probably only consumed oral, non-narcotic, analgesics habitually. This may be one of the factors explaining the difference in incidence between the two Centres because drug taking is much more prevalent in the United States than it is in Australia, but it is difficult to be sure which came first with these patients - the pain or the drug taking.

First Admissions. Sixty-four per cent. of the new admissions to the Austin who had pain at the time of a spot survey were found to have lost that pain on a subsequent survey, compared to 35 per cent. at Rancho.

The period between onset of paralysis and admission to the Centre was very much shorter at the Austin that at Rancho. The great majority of the Austin patients had been treated only at the Austin and not initially by a variety of other hospitals as was invariably the case at Rancho. This delay in admission introduces many potential physical and psychological causes of pain; such as poor management of the spine, both surgical and non-surgical, poor total patient management including inappropriate or inadequate patient counselling; over use of analgesics, including narcotics, and the development of such complications as pressure sores and urinary infection. One or more of these factors were present with most of the patients found to be complaining of pain; in fact the majority of the new Rancho patients had arrived at the hospital with the pain. 
Table VI lists the period of disability for the two Centres, each appearance of the patient in the pain survey being counted. It will be seen that thegreatestnumber of patients at Rancho with pain were between six weeks and six months after onset of paralysis; the Austin patients are more spread out. This distribution of Rancho patients with pain does coincide approximately with the distribution of all patients in the Centre, but it is felt that much of the pain in that period after injury may be explained by the psychological rejection of disability which is maximal at about that time, the period of realisation.

\section{TABLE VI}

Period of Disability (first admissions)

\begin{tabular}{|l|c|c|}
\hline & Austin & Rancho \\
\hline Ist week & 2 & 0 \\
2nd week & 3 & I \\
2-6 weeks & 3 & 7 \\
6 weeks-3 months & I & I7 \\
3-6 months & 6 & 36 \\
6-I2 months & I & I3 \\
Greater than I year & I & 4 \\
\hline
\end{tabular}

Degree of Disability. It was anticipated that the degree of disability might be related to the incidence of pain and support the hypothesis that psychological factors play a major part. Consideration of the neurological levels of patients did not demonstrate a trend towards more pain in tetraplegics in either Centre. On the contrary, paraplegics, particularly those with lesions of the dorsi-lumbar region, showed a disproportionately high incidence of pain as both Centres normally treat a higher proportion of tetraplegics. A greater incidence and severity of pain in the lower lesions has been consistently observed by many previous writers, but not satisfactorily explained by any of them. Possibly a greater difficulty in achieving good anatomical realignment of this region of the spine, compared to the cervical region, is a factor causing this. Alternatively injuries involving nerve roots and the cauda equina may be more painful than spinal cord injuries.

Six of the I4 new patients at the Austin were, at least, potential walkers. Only eight were definitely destined for a wheelchair, compared to 36 out of 46 definite full-time wheelchair patients at Rancho. These proportions are approximately those of walker to non-walkers in the two Centres, respectively.

Pathogenesis of the Lesion. Nine of the Austin patients had fracturedislocations of the spine, three had fractures only. There was one stab wound and one gunshot wound of the spinal cord (both very unusual injuries in Melbourne), and also three non-traumatic lesions.

At Rancho 23 patients had fracture-dislocations of the spine, 12 had fractured vertebral bodies only, Io were due to gunshot wounds and Io to non-traumatic lesions of varied aetiology. There was also one patient who had an extension injury 
of the cervical spine and another who suffered multiple injuries but no injury to the spine, although her main complaint was pain in the spine. It is not considered that the incidence of any of these lesions was out of proportion to their relative proportions in the respective patient communities, except that in both Centres there was only one extension injury of the cervical spine with pain-quite out of proportion to the number of these injuries. It was not possible to confirm a clinical impression that gunshot wounds to the spine are associated with an inordinately high incidence of pain. Ikuta (1970), in reviewing I I I patients treated at Rancho Los Amigos Hospital between I January I965 and 3I December I 969 for spinal cord injuries resulting from gunshot wounds, found that 4I per cent. had pain mentioned as a symptom in their charts, being most common in the lower lesions. This incidence is not significantly different from the overall incidence of pain at Rancho in this survey. Two of the three Austin patients with penetrating lesions had pain, but the numbers are too small to draw any conclusions.

A relatively high proportion of patients with non-traumatic lesions and pain was found in both Centres. As most of these patients had laminectomies performed it is felt that this is the likely common factor rather than the disease process which was very variable.

Drug Abuse. Chronic drug abuse among the re-admitted patients has already been discussed, and was found to be very high at Rancho compared to Austin. However, the association between pain and drug taking was not clear with these patients.

Of the patients admitted for the first time, two Austin patients were known to be chronic drug takers (analgesic tablets) for longstanding osteoarthritis and ankylosing spondylitis which pre-dated their spinal injury. Seven (I 5 per cent.) of the Rancho first admissions were known drug abusers prior to the onset of spinal paralysis - that is, they are known to have been taking drugs habitually without prescription for no apparent organic reason. Two of these were known to be narcotic addicts, the others took a variety of drugs such as barbiturates, amphetamines, marijuana, L.S.D., possibly some heroin also-they were reluctant to discuss details. These figures do not include patients who consumed alcohol excessively. Four of the new Austin patients were known to be moderately heavy drinkers, but could not be considered to be alcoholics. The alcohol habits of the Rancho patients were not known. The figures quoted support a strong impression that people who take alcohol or drugs in large quantities frequently seem to show a lower pain threshold than others not so affected. Possibly the need for drugs or drink and a greater susceptibility to pain are symptoms of the same psychological make up; an inability to cope with different types of stresses, both before and after the onset of the paralysis.

Pain from Non-Spinal Causes. As this survey has been a blanket one including all complaints of pain, a number of patients have been included who have a genuine non-spinal basis for their pain, although it was noted that the complaint was often excessive in time and amount.

At Austin, six patients can be excluded from further study because their pain was obviously due to toothache, abdominal surgery, etc. Similarly, at Rancho I2 patients can be excluded from further study. One patient had pain down the whole of the right side of the body after a cerebro-vascular accident, and two patients 
had a painful arm in association with a brachial plexus lesion above the level of the spinal paralysis; thus 15 in all are excluded.

If these patients are excluded, this leaves a total of I2 Austin patients for further study (one appearing twice) and 45 patients from Rancho. All of these patients had significant pain in the spine, diffuse pain below the level of their neurological lesion, or a nerve root type of pain in the shoulder, arm or trunk. Only one patient (at Austin) had a 'visceral' type of pain as described by Bors (I959), Rossier (I964) and other writers.

Pain of ProbableSpinal Origin. Ten of the 12 Austin patients had fractures or fracture-dislocations, one had a stab wound and one a gunshot wound. Twentynine of the 43 Rancho patients had fractures or fracture-dislocations; seven were due to gunshot wounds and seven were from non-traumatic causes (vascular (3), tuberculosis, neurofibroma, scoliosis and one was of unknown aetiology).

Laminectomy was part of the spinal treatment in two ( 17 per cent.) of the Austin cases and 22 (5I per cent.) of the Rancho patients. Both laminectomies on the Austin patients (not performed at Austin Hospital) were for open wounds and both patients had stable spines despite the operation. All of the laminectomies performed on the Rancho patients had been carried out at other hospitals before their admission to Rancho; 12 were on patients with closed injuries, five on patients with gunshot wounds and five were performed for non-traumatic lesions. Three laminectomies were combined with a posterior fusion and one with an anterior fusion. Only eight of the patients who had laminectomies were proven to be unstable (two of whom had a combined posterior fusion). Six of these patients have had a subsequent anterior fusion but still have the same pain, even though three of them are well past the period when their pain should have been relieved. All six were stable radiologically. Of the remaining I4 patients who had a laminectomy I2 appeared to be stable, while two were not long enough after injury (and operation) for judgement of their stability.

A number of patients with pain had also had spinal fusions performed. Ten (23 per cent.) of the Rancho patients had fusions performed as part of their primary treatment, most at other hospitals. Five of these were posterior fusions (three combined with laminectomy) and five were anterior fusions (one with laminectomy). Four of the fusions were proven to be stable (three anterior), two were proven to be unstable (both combined with laminectomy) and four, two anterior and two posterior, looked to be stable but were too early for functional (stress) films at the time of the survey.

Anterior fusions were performed at Rancho on seven patients for instability, four following laminectomy, two following laminectomy and posterior fusion and one following conservative treatment. All still had pain. Thus, I7 fusions were performed on patients found to have significant pain related to the spine or spinal cord and nerve roots. Fifteen patients had at least one fusion and I I a fusion and no other surgery.

No patients in the Austin series had a spinal fusion. The number of patients in the two Centres who had spinal surgery is summarised in Table VII. It clearly indicates a much higher incidence of surgery among the patients at Rancho who were found to be complaining of pain than at Austin.

Alternatively, Io ( 83 per cent.) of the Austin patients with pain had been treated conservatively, or by non-operative means. One of these had been admitted 
on the day of the survey with an unstable dorsi-lumbar fracture-dislocation, which was operatively reduced and internally fixed the next day. He was free of pain when surveyed one month later. The others fell into two groups: I. five acute patients (between two and 2 I days after injury) whose spines had not united, but only one of whom should still have had pain as he was only 48 hours after injury: and 2. four patients between four and 13 months after injury, all of whom had stable spines and thus no obvious organic explanation for their pain.

Fifteen (35 per cent.) of the Rancho patients with pain were treated conservatively. Only one was unstable, and required surgery, all the others were either proven to be stable or looked as though they would be stable between three and a half weeks and three years after injury, the majority being between three and six months from injury.

The proportion of patients treated by early operation to those treated by conservative means at the two Centres closely approximates the proportions found in this survey with pain. There seems little doubt, therefore, that the much greater amount of early surgery performed on the patients treated at Rancho, most of it

\section{TABLE VII}

Surgery Performed on Patients

\begin{tabular}{|l|c|c|}
\hline & Austin & Rancho \\
\hline As primary treatment & $2(\mathrm{I} 7 \%)$ & $28(65 \%)$ \\
$\begin{array}{l}\text { Delayed treatment } \\
\text { Total }\end{array}$ & $0(\mathrm{I} 7 \%)$ & $29(65 \%)$ \\
\hline
\end{tabular}

N.B. Six of the Rancho patients had primary and delayed surgery for 'instability'.

prior to admission, is the major measurable difference between the patients with pain at Rancho and those at Austin, where most are treated conservatively. This confirms a strong clinical impression that much of the pain seen in these patients was in those who had a laminectomy or a posterior fusion performed, that instability of the spine had little to do with this incidence of pain and therefore delayed fusions would have little beneficial effect on the pain. It is suggested that scarring in the posterior muscular and ligamentous tissues, as a result of the surgery, is a major factor in the causation of the pain. The scarring is much less if the spine is managed conservatively because from the injury itself there is only a small amount of scarring. It is likely, but of course unproven, that the pain of those patients treated conservatively was mainly due to posterior scarring. It is clearly not related to instability of the spine in the great majority.

Suppurative Lesions below the Neurological Lesion. Bors (I959) and Rossier (I964) have noted that pressure sores and other suppurative pathology in paraplegics often accompanies a complaint of pain in anaesthetic areas. Also noted is that the level of pain is often related to the severity of the lesion, or lesions. Because the patients at Rancho are admitted so late compared to those at Austin and have been treated at a variety of non-specialised 'acute' hospitals, it was felt that an 
association between pain below the lesion and pressure sores might be demonstrated.

Only one of the Austin patients (a first admission) had pressure sores, but this could not be blamed for the toothache from dental caries.

Seven (I 5 per cent.) of the 46 new Rancho patients with pain had pressure sores on admission. The incidence of pressure sores among the new patients with pain is probably lower than the incidence in all new patients admitted to Rancho. However, six of the I2 re-admitted Rancho patients with pain had pressure sores. Nine first admissions at Rancho had lesions other than pressure sores below the level of paralysis such as leg injuries.

From these observations there is little evidence that pressure sores and other painful conditions below the level of paralysis had much part in the causation of the pain, except perhaps in the re-admitted group at Rancho, where half of the patients had serious pressure sores. However, it is considered that the connection is a very tenuous one on the basis of this survey, although it is not denied that 'painful' lesions below a level of paralysis may exacerbate a pain of some other origin.

\section{CONCLUSIONS}

A significant difference in the incidence of pain in paraplegic patients in two different Spinal Centres has been demonstrated. To try to explain this difference a close study of the patient material and the methods of treatment has been made.

The first and obvious difference between the two Centres is that the patients treated at Rancho are Americans and those at Austin are Australians. It is not possible to say from this study that Americans have a lower threshold of pain than Australians, but it has been shown that there may be an association between chronic drug abuse, more prevalent in the United States, and the incidence of pain. There did not appear to be any correlation between the ethnic group and the incidence of pain in this study, except that there was an expected high proportion of recent migrants among the Austin group with pain. There did appear to be a greater tendency for females to present with pain problems than males at both Centres; the reason for this is not clear. There was a difference in the age groups involved as there was an unusually high proportion of older patients with pain at the Austin Hospital; theage distribution at Rancho was that of the patient population in the Centre. The incidence of pain among new admissions and re-admissions at both Centres showed no significant trends towards either group.

It was anticipated that one explanation for the difference in the number of patients with pain at the two Centres might be the number of spinal injuries due to open wounds, such as gunshot wounds of the spine, which were a relatively common admission at Rancho but rare at Austin. This did not really establish itself as a significant factor, as the percentage of patients with pain following gunshot wounds was about the same as the percentage of gunshot wounds of the patient population at Rancho. The impression that open wounds are more often associated with pain was not substantiated in this study.

Having found little to explain such a difference in the incidence of pain at the two Centres (other than the unlikely hypothesis that Americans have a three times lower threshold of pain than Australians) it is necessary to consider treatment methods.

Treatment both before and during admission to the Centres must be considered. After non-spinal causes of pain have been excluded and only patients 
with a probably spinal explanation for the pain are studied it was seen that there is a very big difference in the amount of spinal surgery performed on the patients of two Centres. Fifty-one per cent. of the Rancho patients had laminectomies before admission to the Centre compared to I7 per cent. (2) at Austin. This was most unusual for Austin as both patients were delayed admission with open wounds of the spine. Poer (1946) previously reported that 57 per cent. of paraplegics with severe pain had had laminectomies. The pain after laminectomy is not associated with a significant number with instability of the spine, when it is, the pain very often seems to persist after an adequate spinal fusion.

A smaller number of the patients at Rancho who had pain had had spinal fusions as part of their primary treatment. There were none at Austin. A disproportionately high percentage of these operations were posterior fusions. Only a small proportion of patients at Rancho who had had primary anterior fusions were found in the group with pain. It seems inescapable that the scarring associated with operations on the posterior aspect of the spine, such as laminectomy and posterior fusion, is a major factor in the causation of pain in spinal paralytics. This probably also explains the high proportion of non-traumatic spinal paralytics in the group with pain at Rancho-most of them had laminectomies. This hypothesis would appear to be strengthened by the absence of patients with extension injuries of the cervical spine from this group with pain-the soft tissue injury is to the anterior longitudinal ligament and intervertebral disc, not posterior ligamentous structures.

Other treatment factors should also be considered. Little mention has been made so far concerning possible psychological factors causing or aggravating pain. The majority of the patients admitted to Rancho are admitted to that Centre much later than their counterparts at Austin, after primary treatment at another hospital. As well as unnecessary spinal surgery this is often associated with inadequate communication with the patient about his injury and its prognosis.

The author considers that fear of the unknown is very great in the new spinal paralytic and he believes the patient and his relatives should be told the truth about the disability at an early stage. He would disagree with Rossier (I964), who recommends a non-committal approach to the new patient-never making a positive statement concerning the nature of the lesion. The patient should never be made false promises about the likelihood of spinal cord recovery, as was observed to have been done by some doctors, nurses and psychologists prior to their transfer to Rancho Los Amigos Hospital. Apart from this, delay at a non-specialised hospital often results in completely preventable complications such as pressure sores, and such lesions seriously delay the commencement of rehabilitation. A patient forced to lie in bed for weeks or months because of a pressure sore will often become depressed and complaints of pain become frequent.

For both physical and psychological reasons rehabilitation should start immediately after injury, not weeks or months later. The staff of other hospitals probably also contributed to chronic pain syndromes by overuse of analgesics, particularly narcotics. It is considered that few patients require narcotics for more than two or three days after injury. The author considers that the delay in admissions to Rancho is probably a major factor in explaining the difference of pain at the two Centres, rather than differences in the psychological approach, although this also obviously plays some small part as can be seen from the different incidences of pain in different wards at both Centres. 
The author felt that the staff at Rancho spent too much time in conference talking about patients and not enough time talking with patients, but any influence this had on the incidence of pain is impossible to evaluate. Influences of other management details such as the adequacy of reduction and immobilisation of spinal fractures, the place of extensor muscle exercises before getting the patient up and the higher turnover of patients at Rancho could not be gauged from a study such as this. Other previously reported factors, such as irritative lesions below the level of spinal paralysis, have not been shown by this study to be significant.

Spinal surgery, particularly from the posterior aspect, compounded by the physical and psychological problems of delayed admission to a specialised Spinal Centre, seem to be the major factors explaining a big difference in the incidence of pain among paraplegics at two different Centres in different countries. Race, age, disability, cause of injury and chronicity of disability do not appear to be major factors, althout chronic drug taking may be a factor, but it is difficult to separate cause from effect in these patients.

\section{SUMMARY}

A clinical impression of a significant difference in the incidence of pain among spinal paralytics at two Spinal Centres, one in Australia, the other in the United States, has been substantiated by a survey of the patients of the two Centres.

A detailed analysis of the possible factors explaining this difference in the incidence of pain was carried out at the two Centres. It is concluded that spinal surgery, particularly laminectomy, and delayed admission to a specialised Spinal Centre are two important causes of pain in paraplegia.

Acknowledgment. The author would like to express his gratitude to Dr. E. S. Stauffer, Chief of the Spinal Cord Injury Service, Rancho Los Amigos Hospital, and Dr. D. J. E. Cheshire, formerly Medical Director of the Spinal Injuries Unit, Austin HospitalHeidelberg, for their kind permission to use clinical material upon which this study is based.

He is also grateful to the Winston Churchill Memorial Trust and the University of Southern California who made this project possible, and also to the staff of Rancho Los Amigos Hospital and Austin Hospital-Heidelberg, for their assistance with the study.

\section{REFERENCES}

Bors, E. (195I). Arch. Neurol. and Psych. 66, 6 Io.

Bors, E. (I959). Spinal cord injury in Long Term Illness. Management of the Chronically Ill Patient (edited by M. G. Wohl). Philadelphia \& London: p. 469-480. W. B. Saunders Co.

Bors, E. (I963). Proceedings of a Symposium on Spinal Injuries, Royal College of Surgeons, Edinburgh, p. 15-32.

Botterell, E. H., Callaghan, J. C. \& Jousse, A. T. (1953). Proc. Roy. Soc. Med. 47, 28I. Davis, L. \& MarTin, J. (1947). F. Neurosurg. 4, 483.

Evans, J. H. (1962). Brain, 85, 687.

IKUTA, C. (I970). Personal communication.

KENNEDY, R. H. (1946). Annal. Surg. 124, 1057.

Munro, D. (1948). Amer. F. Surg. LXXV, 3.

Munro, D. (I950). New England F. Med. 242, I.

PoER, D. H. (1946). Annal. Surg. 123, 5 IO.

RIDDOCH, G. (I9I7-I8). Brain, 40,617.

RIDDOCH, G. (I94I). Brain, 64, I97. 
Rossier, A. B. (1964). Rehabilitation of the spinal cord injury patient, Documenta Geigy Acta Clinica, No. 3, North American Series, pp. 80-82.

SHERRINGTON, C. (I952). The Integrative Action of the Nervous System. 1952 edition, pp. 229-230. Cambridge University Press.

Weinstein, S. (I962). Proceedings of the IIth Annual Spinal Cord Injury Conference, Veterans Administration, 138 .

Wilcox, N. E., Stauffer, E. S. \& Nickel, V. L. (I970). Int. F. Paraplegia, 8, 27.

\section{Discussion}

Mr. P. HARris (G.B.). I would like to ask Dr. Burke about the situation regarding cauda equina injuries. It has been one's experience over the years, especially in relation to World War II patients, that partial cauda lesions, in particular, appear to develop intractable pain. Would he care to comment on this?

Dr. A. G. Hardy (G.B.). One important observation I would like to make and one question to follow it. I think it is absolutely essential that we define pain better than in Dr. Burke's series. I am concerned with two types of pain: pain with a reference to the paralysed areas and pain with a reference to the injury site. And I would like to ask Dr. Burke whether it is possible, from his series, to separate those two types of pain.

Chairman. I'm going to give myself just a minute to make a brief comment on this matter of defining pain. If one specifically asks a patient about pain-if you actually go up to a patient and say 'Do you have any pain or have you had any pain this week ?'our experience is that a much greater number of patients will say that they have. They never complain about the pain spontaneously. Now, with regards to the criterion, it seems to me from experience in my own service where I have been in the habit of making weekly drug rounds to see what drugs ward physicians are giving; and where I have to the best of my ability, discouraged the use of drugs-and I don't mean the heavy sort of hard drugs, but the simple analgesics like aspirin and Darvon. Many people are prescribed these simply because the doctor doesn't want to be bothered. A patient may tell the doctor that he is suffering from pain in the leg and the doctor will order Io grs. of aspirin three or four times a day. I wonder how many so-called healthy people would answer 'yes' to the question 'Have you had any kind of pain in the last week'? I think the number would be very great, especially in the United States where the television advertisements insist that nobody should endure any kind of discomfort, however slight, for more than 15 minutes.

It seems to me that from our point of view the distinguishing feature of pain is whether or not it is disabling and whether or not we can, by reasonable means, enable the patient to live with it. Sir Ludwig will remember a symposium in 1957, pain being one of the topics, at which I pointed out that distraction was an enormously valuable instrument in the management of pain. As an example of this I mentioned a series of six of my patients who never once complained of pain again af ter they got marriedalthough most people agreed that this was rather drastic treatment.

Also I don't want to say anything against Rancho but I think they do a hell of a lot too much operating. And when a patient has been getting post-operative medication he's going to keep on asking for it for the rest of his hospital stay if possible. That happens even to patients who receive surgery in other areas.

Sir Ludwig GutTman (G.B.). I think we could really have a full-day discussion on pain, because there is so much to be said about it. I was very impressed to hear Dr. Burke tell us about the high incidence of pain after laminectomy and after fusion but I was not surprised because that is exactly what I have observed for many years. People who, before operation, had never complained of pain now did, particularly those who had a 
fusion for stabilising the spine. If you take follow-up X-rays after the so-called stabilisation the deformity of the spine explains why the people have pain. It is because they have a much more marked deformity than they ever would have had had they been left alone.

I would have liked, of course, for Dr. Burke to have told us a little more about the definition and localisation of pain; Dr. Hardy has already mentioned two localisations. I think we have to (a) distinguish between the acute pain, mentioned by Dr. Burke, and $(b)$ to also consider, in the acute stages, the painful phantom sensation. I was very surprised to find that in both Austin and Rancho there were very few incidences of phantom sensation because whenever a patient is asked about pain just after an operation he will tell you that he has an unpleasant sensation in his legs, or he feels as if they have been blown off. That is a very interesting phenomenon and I feel that all people concerned with the immediate treatment of patients should go into the matter systematically. In my publications of the 1957 symposium, mentioned by Dr. Talbot, and in my book on spinal injuries which will appear in May 1973, I have mentioned this in more detail. But apart from the localisation of pain below the level of the lesion, which in particular occurs in cauda equina lesions, there may occur pain in complete lesions just at the level of the lesion as a result of either root irritation or irritation of the distal segment of the proximal part of the cord above the transection. These are interesting phenomena because the afferent irritation, experienced as pain, can produce various and often very awkward nociceptive responses of the muscular as well as the autonomic systems. But there are two other types and localisations of pain: first, I think Dr. Burke has mentioned that tetraplegics, particularly those who had not received proper treatment, developed pain in their shoulder or elbow joints. This pain can be extremely difficult to treat, but if you have good physiotherapists this kind of pain will disappear completely once the joints are in a supple condition. I showed you just this morning a tetraplegic patient who was admitted with profound contractures of the elbow. This neglect in management is a terrible thing, and I call this an iatrogenic pain because these unfortunate people haven't been treated properly. Secondly, there is pain and autonomic nociceptive responses above the level of the cord lesion including headache as the result of hyperactivity of viscera below the level of the lesion, particularly distension of the bladder. The use of aspirin or codein, in these patients, given indisciminately by the nursing staff or even by the doctor who doesn't understand the whole thing, can be most dangerous if a distension of the bladder, for instance by a blocked catheter, is overlooked. These pain sensations are conducted by the autonomic fibres along the vessels. I would have liked to ask Dr. Burke whether he had distinguished these various origins of pain in his series of cases.

Dr. D. Burke (Australia). Some of these questions overlap so I'll try and summarise the answers. First of all the reason for my paper is that it will stimulate some more on the subject because obviously there's still a lot unknown.

Mr. Harris - cauda equina lesions were out of proportion among the patients with pain, as would be expected from other reports on the subject. I thought that there might be a high proportion of high cervical lesions because of the disability and the psychological factors, but this wasn't so, they were quite low in number.

I agree with Dr. Hardy that a better definition of pain was required, and in fact I was very careful not to define pain in my paper other than by arbitrary definition for the selection of patients. I believe that Sherrington's definition is still the best one-the psychical adjunct of an imperative protective reflex.

I included everything as pain including toothache and pain resulting from abdominal surgery. The great majority had pain in the spine, either in the neck or the back depending on the level of injury and/or some nerve root radiation. There were only four with a true phantom type of pain below the lesion and only one of the visceral type of pain which was also below the lesion. This was rather surprising in relation to what I had read 
in some of the journals prior to this. It is unfortunate that we don't have a pain meter to measure pain-it would have made the paper much easier.

In answer to Dr. Talbot, many patients at Rancho were admitted while on drugs (mainly of the aspirin type). They had been receiving treatment for many weeks from other hospitals before they came to Rancho, and to my knowledge no morphia had been prescribed. I didn't ask the patients if they had pain, I did this deliberately as I felt I would make more errors by omission or addition if $I$ had. The selection of patients was mainly my own with the help of an experienced sister, who knew the patients in both Centres at the time. You will notice that I didn't conduct this survey until quite late in my time at Rancho, so I also knew the patients quite well.

I should also reiterate, I did say this but I want to make it quite clear, that the laminectomies and most of the early fusions were performed at other hospitals before being admitted to Rancho. They may have had another fusion somewhere along the way, but if they did, this didn't seem to alter the presence or absence of the pain.

And just one final point on phantoms. I feel that a lot of the patients at Rancho, particularly, who had pain were in fact complaining of a phantom. It probably started off as the fairly common tingling or cold feeling and because nobody would take any notice or give them an explanation of this complaint they gradually changed the symptom into one of pain; knowing that the moment they mentioned it the doctors and nurses would come running. 